INTERNATIONAL JOURNAL OF RESEARCHES IN BIOSCIENCES, AGRICULTURE AND TECHNOLOGY

(C) VISHWASHANTI MULTIPURPOSE SOCIETY (Global Peace Multipurpose Society) R. No. MH-659/13(N) www.vmsindia.org

\title{
INFLUENCE OF CERTAIN SUBSTITUTIONS IN Ni-Zn SPINEL FERRITES-A REVIEW
}

\author{
D. S. Choudhary \\ Dhote Bandhu Science College, Gondia (MH) \\ dschoudhary@dbscience.org
}

\begin{abstract}
:
In the recent years, there has been an increased interest in the application of $\mathrm{Zn}$ substituted ferrites, in particular $\mathrm{NiCuZn}$ ferrites for the production of MLFCI components. Further, The applications of the ferrite chip inductors include combined inductor-capacitor (LC) filters, Electromagnetic Interference (EMI) filters, an AC choke for active devices, matching circuits, electromagnetic suppressor etc. apart from audio and visual equipment. Due to such potential applications, several studies have been conducted to enhance the properties of NiCuZn ferrite. Important approaches adopted are: a) the reduction of the particle size to improve densification, b) using sintering aids for better densification and c) substitutions at tetrahedral and octahedral crystallographic site in the spinel ferrite to improve electromagnetic properties. The work during last few years on Zn-spinel ferrites for the morphological, electromagnetic and dielectric and other properties has been reviewed. It is observed that the Permeability and resistivity are the most important parameters used in evaluating magnetic materials. The electromagnetic properties of NiCuZn ferrites are highly sensitive to the processing parameters especially sintering conditions and the amount of constituent metal oxides. Therefore, the investigation for various compositions in the $\mathrm{Ni}-\mathrm{Zn}$ ferrite is carried out globally. In present article the work on NiZn ferrite in last recent years is reviewed and inferred that chemical composition and the substitutions-aid in ferrites must be used as attractive approaches to modify the potential properties.
\end{abstract}

Keywords- NiCuZn ferrite, nano-ferrite, dielectric loss factor, magnetization, conductivity.

\section{Introduction:}

It is well-known that the magnetic ceramics with iron oxide as the major constituent are termed as Ferrites. Since last seven decades ferrites have been marked as an important new category of magnetic materials. These are now very well established group of magnetic materials. Today ferrites have truly wide range of potential applications, and have contributed materially to the advances in electronics. In the area of new materials, ferrites with permeability up to 30,000 and power ferrites for frequencies up to $10 \mathrm{MHz}$ have been made available commercially [1]. Even though, improvements and innovations continue to take place; many new applications, theories and preparation technologies are currently under development in field of ferrites.

In the last two decades, latest advancement in wireless technology has explored the area of real-time communication. Internet-accessible cell phones and high-speed wireless local area network are the best examples of this technology. The core of these systems is based on a radio frequency [RF] circuit consisting of transmission and receiving circuit blocks required in signal amplification, filtering, and modulation that in turn require hundreds of passive chip components such as capacitors and inductors. Presently, NiCuZn ferrites have been the dominant materials for MLFCI and electromagnetic suppression due to it slow sintering temperature $\left(<950^{\circ} \mathrm{C}\right)$ and good electromagnetic properties. In addition, $\mathrm{NiCuZn}$ ferrites have better high frequency properties compared to that ofMnZn ferrite and low densification temperatures than $\mathrm{NiZn}$ ferrites $[2,3]$.

Permeability and resistivity are the most important parameters used in evaluating magnetic materials. The electromagnetic properties of $\mathrm{NiCuZn}$ ferrites are highly sensitive to the processing parameters especially sintering conditions and the amount ofconstituent metal oxides in their composition $[4,5]$. Considering the scope many researchers investigate for various compositions in the system $\left(\mathrm{Ni}_{1-\mathrm{x}-\mathrm{y}} \mathrm{Zn}_{\mathrm{x}} \mathrm{Cu}_{\mathrm{y}}\right) \mathrm{Fe}_{2} \mathrm{O}_{4}$. The work on $\mathrm{Zn}$ substituted $\mathrm{Ni}$ ferrite is observed multidisciplinary in nature. Some investigations in last few years has been reviewed in the present article keeping a view that some useful result may come up in the contest of research and development.

\section{Experimental Findings}

Many investigators have focused their attention on the improvement of electromagnetic properties of the ferrite by divalent ions substitution. Generally, the divalent metal ions $\left(\mathrm{M}^{2+}\right)$; $\mathrm{Ni}, \mathrm{Zn}, \mathrm{Cu}, \mathrm{Mg}, \mathrm{Mn}$, Co or mixtures of these are substituted in different spinel ferrites. These substitutes have different sitting preferences for the two sites ('A' and 'B') in the spinel structure and can change many properties as an effect of modified cation distribution in the ferrite. On the basis of site distribution of $\mathrm{M}^{2+}$ ions and the strength of the exchange interaction among magnetic ions, the 
influence of $\mathrm{M}^{2+}$ substitutions on electromagnetic properties can be explained. The effect of different divalent cations in NiCuZn ferrite, along with some other spinel ferrites is reviewed below.

Naveen Kumari et al synthesized $\mathrm{ZnFe}_{2-}{ }_{-} \mathrm{Cr}_{x} \mathrm{O}_{4}(x=0,0.1,0.3,0.5)$ ferrite nanoparticles by a chemical co-precipitation method. The magnetization studies inferred that magnetic moment $(\eta B)$ showed decreasing trend with increase in $\mathrm{Cr}^{3+}$ substitution, its value decreases from 0.548 (for $x=0.0$ ) to 0.125 (for $x=0.5$ ). The saturation magnetization (MS) value was found to decrease from $12.76 \mathrm{emu} / \mathrm{gm} \quad$ (for $x=0.0$ ) to $2.92 \mathrm{emu} / \mathrm{gm}$ (for $x=0.5)$. The coercivity $(H c)$ was found to change proportionally with the particle sizes of investigated ferrites. Squareness $(S)$ values revealed that particles interact by magnetostatic interactions. The $M-H$ loop of all the samples is narrow with low value of coercivity and retentivity; indicate the superparamagnetic nature of these samples [6].

Nanocrystalline powders of chromium and aluminum co-substituted zinc ferrites with general formula $\mathrm{ZnFe}_{2-2}{ }_{x} \mathrm{Cr}_{x} \mathrm{Al}_{x} \mathrm{O}_{4}(0 \leqslant x \leqslant 1)$ have been synthesized by Adrian I. Borhan et al. The all compounds found as mixed ionic distribution[7]. The magnetic measurements showed that the hysteresis losses and the magnetization at $10 \mathrm{KOE}$ linearly decreased when the $\mathrm{Cr}-\mathrm{Al}$ content in $\mathrm{Zn}$ ferrite increased. The results obtained in dielectric study showed very low values of dielectric loss at frequencies over $1 \mathrm{MHz}$.

Santosh Bhukal et al [8] have synthesized chromium substituted $\mathrm{Co}-\mathrm{Zn}$ nanoferrites having the formula Co0.6 $\mathrm{Zn}_{0.4} \mathrm{Cr}_{x} \mathrm{Fe}_{2-x} \mathrm{O}_{4}(x=0,0.2,0.4,0.6,0.8$ and 1.0) using the sol-gel auto-combustion method. And single-phased cubic spinel structure having space group $\mathrm{Fd}-3 \mathrm{~m}$ for all the annealed samples is reported. The lattice parameter has been observed to decrease with increasing substitution of $\mathrm{Cr} 3+$ ions because of the smaller ionic radii of $\mathrm{Cr}^{3+}(0.68 \hat{\AA})$ as compared to $\mathrm{Fe}^{3+}(0.73 \AA)$. The electrical resistivity increases with increasing $\mathrm{Cr} 3+$ concentration attributing to the reason that electrical conductivity decreases with decrease in $\mathrm{Fe}$ concentration because of the decrease in polaron hopping of $\mathrm{Fe}^{2+}-\mathrm{Fe}^{3+}$ ions. The resistivity of all the annealed samples decreases with increasing temperature showing the semiconductor nature of the samples. The drift mobility also increases with increasing temperature because of the enhanced mobility of charge carriers due to thermal activation. The saturation magnetization $(M s)$ decreases with increasing chromium content, due to the lower magnetic moment of $\mathrm{Cr}^{3+}$ ion $(3 \mu \mathrm{B})$ than that of $\mathrm{Fe}^{3+}$ ion $(5 \mu \mathrm{B})$.

The effect of $\mathrm{Cr} 3+$ substitution in $\mathrm{Mg}-\mathrm{Zn}$ ferrite, with a chemical formula $\mathrm{Mg}_{0.5 \mathrm{Zn}} \mathrm{Z}_{5} \mathrm{Cr}_{x} \mathrm{Fe}_{2-} \mathrm{O}_{4}(x=0.0-1.0)$, synthesized by Haralkar S.J. et al. The XRD pattern revealed the cubic spinel [9]. The cation distribution suggests that $\mathrm{Mg}^{2+}, \mathrm{Cr}^{3+}$ and $\mathrm{Fe}^{3+}$ have strong preference towards octahedral B-site. The theoretical lattice constant and experimental lattice constant match each other very well. The IR analysis supports the presently accepted cation distribution. The saturation magnetization decreases linearly with increasing $\mathrm{Cr}^{3+}$ content. The dc resistivity has been investigated as a function of temperature and composition.

Nano-crystalline ferrites; $\mathrm{Co}_{0.9} \mathrm{Zn}_{0.1} \mathrm{Fe}_{2-x} \mathrm{Cr}_{x} \mathrm{O}$ (where $x=0-1$ ) have been synthesized by Gabal M.A. et al through thermal decomposition reaction. XRD revealed singlephase $\mathrm{c}^{3+}$ ubic spinels. Both crystallite size and lattice parameter decreases with increasing $\mathrm{Cr}$ content. FT-IR spectral studies confirmed the suggested cation distribution estimated through XRD measurements. TEM image showed agglomerated spherical nanoparticles with size of about $20 \mathrm{~nm}$. The gradual decrease in the saturation magnetization, estimated through VSM measurements, with increasing $\mathrm{Cr}$-content suggests the preferential occupation of $\mathrm{Cr}$ ions in the octahedral sites and confirmed the suggested cation distribution while, the decrease in the coercivity values indicating the loss of magneto-crystalline anisotropy. The decrease in the Curie temperatures obtained from dc-magnetic susceptibility with the increasing chromium can be attributed to the decrease in the A-B exchange interaction. [10]

Alone S.T. et al prepared Nanoparticles of $\mathrm{Co}_{1-x} \mathrm{Zn}_{x} \mathrm{Fe}_{2-} \mathrm{Cr}_{x} \mathrm{O}_{4}(x=0.0-0.5)$ ferrites were by chemical co-precipitation technique using metal sulphates. X-ray diffraction patterns indicate that the samples possess single phase cubic spinel structure. The lattice constant initially increases for $x \leq 0.3$ and thereafter for $x>0.3$ it decreases with increasing $x$. The saturation magnetization (Ms), magneton number $(n \mathrm{~B})$ and coercivity $(\mathrm{Hc})$ decreases with increasing $\mathrm{Cr}-\mathrm{Zn}$ content $x$. Curie temperature deduced from AC susceptibility data decreases with increasing $x$. [11]

Nano-sized ferrites of compositions ( $\mathrm{Ni}_{0.6} \mathrm{Cu}_{0.20} \mathrm{Zn}_{0.20} \mathrm{Fe}_{2-} \mathrm{Cr}_{x} \mathrm{O}_{4}$ ), $\quad$ where $x=0-1.0$, were synthesized through nitrate-citrate auto- 
combustion method at relatively low temperature by Gabal M.A. and Al Angari Y.M. XRD revealed the formation of nano-sized ferrite particles with cubic spinel structure. An exception was obtained for samples with $\mathrm{Cr}$ content $\leq 0.2$, where weak diffraction peaks attributed to the presence of $\mathrm{CuO}$ and $\mathrm{Fe}_{2} \mathrm{O}_{3}$ were appeared. The average crystallite sizes are much dependent on the chromium content and were found to decrease with its increase. The lattice parameter (a) slightly decreases with $\mathrm{Cr}$ substitution, which can be explained on the basis of the relative ionic radii of $\mathrm{Cr}^{3+}$ and $\mathrm{Fe}^{3+}$ ions. X-ray density was found also to decrease slightly with increase in chromium content, which indicates lower densification by the addition of $\mathrm{Cr}$. FT-IR measurements show the characteristic ferrite bands. Electrical property measurements revealed that $\mathrm{Cr}^{3+}$ ions do not participate in conduction process but limit the degree of $\mathrm{Fe}^{3+}-$ $\mathrm{O}^{2-}-\mathrm{Fe}^{3+}$ conduction resulting in a decrease in the conductivity and increase in conduction activation energy. [12]

Bayoumy W.A. and Gabal M.A. used egg-white method to produce nanocrystalline Cr-substituted NiCuZn ferrites; $\mathrm{Ni}_{0.50} \mathrm{Cu}_{0.25} \mathrm{Zn}_{0.25} \mathrm{Fe}_{2-} \mathrm{Cr}_{x} \mathrm{O}_{4}(0.0 \leq x \leq 1.0)$ from stoichiometric mixture of their respective metal nitrate. The average crystallite sizes obtained from XRD were between 15 and $25 \mathrm{~nm}$. Magnetization measurements indicated that when the $\mathrm{Cr}$ substitution increases the saturation magnetization decreases due to the magnetic character of the chromium ions which prefers octahedral site occupation. The coercivity was found to change proportionally with the particle sizes of the investigated ferrites. [13]

\section{Result and Discussion:}

$\mathrm{Zn}$ ferrite with different ferromagnetic elemental such as $\mathrm{Ni}$, Co has been extensively studied for their substitution effects on various morphological and electromagnetic behaviors. It is observed that $\mathrm{Cu}$ is used in this ferrite to decrease the sintering temperature. However, $\mathrm{Cu}$ decreases the resistivity of the ferrite, which is not desirable for its high frequency applications. So, optimization of $\mathrm{Cu}$ content with respectto densification and resistivity of the ferrite is very important. Different ranges of electromagnetic properties have been reported with various $\mathrm{Zn}$ concentrations in NiCuZn ferrites. Optimization of $\mathrm{Zn}$ concentration with respect to $\mathrm{Ni}$ and $\mathrm{Cu}$ is essential to achieve desirable electromagnetic properties in the ferrites where, $\mathrm{Zn}$ enters into the 'A'sites by displacing a proportionate number of $\mathrm{Fe} 3+$ from 'A' to 'B' sites. Therefore, effect of cation substitution in optimized $\mathrm{NiZnCu}$ ferrite must be considered for the study. One of the key parameters to change the permeability in spinel ferrite is lowering the magnetostriction constant. Hence, Cobalt can be substituted for $\mathrm{Ni}$ to change the permeability in optimized $\left(\mathrm{Ni}_{1-\mathrm{x}-\mathrm{y}-}\right.$ $\left.{ }_{z} \mathrm{Co}_{\mathrm{x}} \mathrm{Cu}_{\mathrm{y}} \mathrm{Zn}_{z}\right) \mathrm{Fe}_{2} \mathrm{O}_{4}$ ferrite where, Co enters into the 'A' sites by displacing a proportionate number of $\mathrm{Ni}^{2+}$. Influence of rare earths on the properties of different ferrites has been reported by many investigators. Rare earth ions can improve densification and increase permeability and resistivity in $\left(\mathrm{Ni}_{1-\mathrm{x}-\mathrm{y}} \mathrm{Zn}_{\mathrm{x}} \mathrm{Cu}_{\mathrm{y}}\right) \mathrm{M}_{\mathrm{z}} \mathrm{Fe}_{2-\mathrm{z}} \mathrm{O}_{4}$ ferrites where, $M$ enters into the ' $\mathrm{B}$ ' sitesby displacing a proportionate number of $\mathrm{Fe}^{3+}$ from 'B' sites. Further, CoZn nano ferrites have been extensively studied because of their many industrial applications. $\mathrm{Cr}$ has been found to enhance the density, so that it can be used in high density magnetic recording media. Chromium doping reduces the saturation magnetization, so that it can be utilized in materials with low magnetization. The substitution of $\mathrm{Cr}$ leads to enhance the DC resistivity for its utility in high resistive materials. The increase in $\mathrm{Cr}^{3+}$ concentration in the $\mathrm{Ni}-\mathrm{Zn}$ ferrite caused a reduction in hysteresis losses and a slight reduction in the saturation magnetization.[14]

\section{Conclusion:}

Summarizing to the all it clear that the chemical composition and the substitutions-aid in ferrites have been used as attractive approaches to modify the structural, electromagnetic, dielectric properties etc. It is noted that the permeability, resistivity, thermoelectric properties are also dependent of the densification and microstructure of the ferrite. Interestingly, it is revealed that for fixed concentration of $\mathrm{Cu}$, the optimized $\mathrm{NiCuZn}$ ferrite may be developed for the desired lossless substances. Further, the different cations substitutions and their significant effects on the characteristics of the ferrites give new kind of smart material having the potential application.

\section{References:}

[1] Goldman A., "Recent Advances in Ferrite Materials Technology," in Modern Ferrite Technology, Van Nostrand Reinhold, New York, (1990).

[2] Jean J. H., Lee C. H. and Kou W. S. (1999): J. Am. Ceram. Soc. 82 (2): Pp. 343. 
[3] Stoppels D. (1996): J. Magn. Magn. Mater. 160 :Pp. 323.

[4] Caltun O. F., Spinu L., Stancu Al., Thung L. D. and Zhou W. (2002): J. Magn. Magn. Mater (160): Pp. 242-245.

[5] Hsu J. Y., Ko W. S., Hen H. D., Chen C. J. (1994): IEEE Trans. Mag. 6 (30): Pp. 4875.

[6] Naveen Kumari, Vinod Kumar, Khasa, S, and Singh S.K. (2015): Chemical synthesis and magnetic investigations on $\mathrm{Cr}^{3+}$ substituted Zn-ferrite superparamagneticnano-particles. Ceramics International 41 (1): Pp.1907-1911.

[7] Adrian I. Borhan, Vasile Hulea, Alexandra R. Iordan and Mircea N. Palamaru (2014): $\mathrm{Cr}^{3+}$ and $\mathrm{Al}^{3+}$ co-substituted zinc ferrite: Structural analysis, magnetic and electrical properties.Polyhedron 70: Pp. 110118.

[8] Santosh Bhukal, Tsering Namgyal, Mor S., Bansal S. and Sonal Singhal (2012): Structural, electrical, optical and magnetic properties of chromium substituted $\mathrm{Co}-\mathrm{Zn}$ nanoferrites

Co0.6Zn ${ }_{0.4} \mathrm{Cr}_{x} \mathrm{Fe}_{2-} \mathrm{O}_{4}(0 \leqslant x \leqslant 1.0)$ prepared via sol-gel auto-combustion method. Journal of Molecular Structure (1012): Pp.162-167.

[9] Haralkar S.J., Kadam R.H., More S.S, Shirsath Sagar E., Mane M.L., Swati Patil, Mane D.R. (2012): Substitutional effect of $\mathrm{Cr}^{3+}$ ions on the properties of $\mathrm{Mg}$ $\mathrm{Zn}$ ferrite nanoparticles. Physica B: Condensed Matter 407 (21): Pp. 4338-4346.
[10] Gabal M.A. , Al AngariY.M. and Al-Agel F.A. (2013): Synthesis, characterization and magnetic properties of Cr-substituted Co- $\mathrm{Zn}$ ferrites nano powders. Journal of Molecular Structure (1035): Pp. 341-347.

[11] Alone S.T., Shirsath Sagar E., Kadam R.H. and K.M.(2013): Chemical synthesis, structural and magnetic properties of nanostructured Co-Zn-Fe-Cr ferrite Journal of Alloys and Compounds509(16): Pp. 50555060.

[12] Gabal M.A. and Al Angari Y.M. (2010):Lowtemperature synthesis of nanocrystalline $\mathrm{NiCuZn}$ ferrite and the effect of $\mathrm{Cr}$ substitution on its electrical properties:Journal of Magnetism and Magnetic Materials 322 (21):Pp. 3159-3165.

[13] Bayoumy W.A. and Gabal M.A. (2010): Synthesis characterization and magnetic properties of Cr-substituted NiCuZn nanocrystalline ferrite:Journal of Alloys and Compounds 506(1):Pp. 205-209.

[14] Costa A.C.F.M., Silva V.J., Ferreira H.S., Costa A.A., Cornejo D.R., Kiminami R.H.G.A. and Gama L.(2008) :Structural and magnetic properties of chromium-doped ferrite nano powders: Journal of Alloys and Compounds483(1-2): Pp. 655-657. 